\title{
RETINITIS STELLATA IN CONNECTION WITH FOCAL INFECTION
}

BY

BÉla BOROS, M.D.

FROM THE DEPARTMENT OF OPHTHALMOLOGY OF THE ELISABETHUNIVERSITY, PÉCS, HUNGARY

PROFESSOR: DR. CONRAD ALBRICH

RETINITIS STELlata is a very easily observed disease but its causes and the conditions under which it occurs are not yet fully known. It is well known, that the easily recognizable star-shaped figure always characterizes retinitis coming from the kidneys, but it is also true that this star-shaped figure may sometimes be present when no kidney trouble can be found. But the causes in such cases are not yet discovered in spite of very careful examinations. Leber has classified such retinal diseases, according to aetiology into the following four groups :-

1. Retinitis appearing on one side only. This is mostly found in young individuals and is of long duration. Its causes are unknown.

2. Retinitis appearing after influenza. This is quickly cured.

3 . This group consists of cases of retinitis stellata which accompany chlorosis. Such cases are usually bilateral, and cease with the disappearance of the chlorosis.

4. Retinitis stellata usually caused by emboli and thrombosis always appearing in connection with disturbances of blood circulation.

Apart from Leber, Sidler-Huguenin found that retinitis is sometimes due to tuberculosis, Dauko has attributed it to meningitis, Schieck to Korsakoff's disease, Merkulov to brain tumour, Pascheff to ureteric infection, while Zanettin has found cases where it is usually due to injuries of the skull.

Two interesting cases have been published by Neuber in one of which retinitis stellata appeared in connection with a foreign body in the orbit, and the other with furunculosis of the temples.

The number of observations regarding retinitis stellata caused by focal infection and infection of the teeth is rather small. Hessberg in his monograph mentions that Hillmann was the only person who had published such a case. Therefore we find it worth while to describe such a case observed in our clinic.

A woman patient, aged 42 years, complained that her vision grew suddenly bad. She consulted us three weeks later.

Anamnesis did not afford any information. Externally her eyes were intact. The vision of the right eye was finger counting at 15 metres, of the left eye normal. The optic disc was filled with 
blood, and the contours were indistinct. The proportion between the arteries and veins was normal, except in the case of the inferior temporal vein which was thicker. There was no bleeding. Small white glistening spots were found along the vessels around the disc, towards the macula. These increased in number. Around the macula the star figure was strikingly regular in design. No kidney trouble or other organic trouble of any kind could be observed. Blood pressure : $130 / 85 \mathrm{Hg}$. Complement negative. No increase in blood sugar or cholesterin. Tuberculin test negative. Nose and sinuses not pathological. Teeth in bad condition : upper 8 , lower 2 roots and 3 carious teeth. We applied amyl nitrite inhalation for ten days, after which the vision and fundus showed no change. Ten of her bad teeth were extracted. A few days after this the vision improved to $6 / 36$ and later to $6 / 24$, and 12 days after the extraction of the teeth her vision was $6 / 12$. In spite of the greatly improved vision the fundus showed no significant change. Three months afterwards her vision became normal and the fundus became normal with the exception of a few remaining tiny white spots.

As the above described changes in the fundus are considered according to certain authors pre-albuminuric signs, we reexamined the patient's kidneys, but the result was negative.

Although focal infection is difficult to detect according to all known definitions (Billing), yet in the above case improvement in the vision was so great after the extraction of the teeth, that we cannot deny the connection between the focal infection and the teeth.

The theory of focal infection introduced by Pässler (1909), Rosenow, Hunter, Billing has given rise to a tendency to overrate the rôle of the teeth. The explanation of this lies in the fact, that our knowledge regarding focal infections is based on clinical observation only, while our pathological and ætiological knowledge is still-as Grumbach says-in an undeveloped stage. An ætiological conclusion can only be drawn, if after the removal of the focus complete recovery occurs, i.e., with the disappearance of all pathological signs.

Considering those anatomical and histological examinations, which make clear the connection between the eyes and the teeth through vessels and lymph apparatus and considering a series of eye diseases originating from teeth, we have to suppose that the extraction of bad teeth resulting in definite healing of the retina as seen in our case, is a fact which cannot be overlooked.

Thus we can conclude that an ætiological connection exists between the focus and the retinitis stellata and therefore we have to suppose, that the endothelial disturbances (Marx, Hellmut) and spasms in the retinal vessels are caused by microbes or toxins 
carried from the focus into the circulation. As a consequence of this a deficiency in nutrition occurs causing the disease of the retina.

Consequently when diagnosing retinitis stellata we should give significance to the rôle of the teeth.

\section{LITERATURE}

BENCE.-The clinical significance of focal infection. Lecture given in the Hungarian Medical Congress in 1935.

BORSOS-NACHTNEBEL.- The pathological connections of the focal infection. Ibidem.

Hessburg.-Die Beziehungen zwischen Augen u. Zahnkrankheiten. Zentralbl. f. Ophthal., Bd. XXIX.

HIPPEL.-Arch. of Ophthal., Bd. CXXVIII.

HORAY.-Focal infection from the point of view of the eye.

KAMINSKIJ.-Zentralbl.f. Ophthal., Bd. XXII.

LEBER.-Graefe-Saemisch Handbuch, Bd. XLI-II.

MER KULOV -Zentralbl.f. Ophthal., Bd. XXXII.

\section{ANNOTATION}

\section{The Blind Spot}

Abbé Edme Mariotte (1620-1684) probably communicated his discovery of the blind spot to the Académie royale des Sciences in the winter of 1667-8. It was first published in a letter to M. Jean Pecquet in 1668. On May 7,1668, Mr. Oldenburg, Secretary of the Royal Society, "produced an experiment sent him from Paris "by the no less obliging than ingenious Monsieur Justel" (Phil. Trans., Vol. III, p. 668. 1668), showing that when the picture of an object falls just on the optic nerve there is no vision." (Th. Birch, History of the Royal Society of London, Vol. II, p. 281, 1754). Helmholtz, in his "Handbuch der physiologischen Optik," p. 222, 1867 states: "Der Versuch erregte damals solchen Aufsehen dass er ihn 1668 vor dem Könige von England wiederholte." Dr. J. Bröns, of Copenhagen, in his excellent monograph on "The Blind Spot of Mariotte" (H. K. Lewis, 136, Gower Street, London, 1939), proves that this statement is erroneous, and brings forward strong evidence of the manner in which it arose.

In 1776, Georg Simon Klügel, Professor of Mathematics in the University of Helmstädt, published a translation of Joseph Priestley's "The History and present state of Discoveries relating to Vision, Light and Colours" (London, 1772). On page 144 of the translation there is a foot-note as follows: "(a) Smith's Opticks, Remarks, p. 6 (d. d. Ausg. S. 367.) Oeuvres de Mariotte, p. 496. (Der Versuch ist 1668 vor dem Könige von England gemacht. Birch, T. 2, p. 281. Haller's Phys., T. 5, p. 470, K.") The 